\title{
Terre des Lasers: the new Aquitaine outreach and communication center in photonics
}

Jean Paul Prulhiere, Laurent Sarger

Jean Paul Prulhiere, Laurent Sarger, "Terre des Lasers: the new Aquitaine outreach and communication center in photonics," Proc. SPIE 9666, 11th Education and Training in Optics and Photonics Conference, 96660D (5 June 2009); doi: $10.1117 / 12.2208022$

SPIE Event: Eleventh International Topical Meeting on Education and Training in Optics and Photonics, 2009, St. Asaph, United Kingdom 


\title{
« Terre des Lasers »: The new Aquitaine Outreach and communication center in photonics
}

\author{
Jean Paul PRULHIERE, Head of project - ALPhA-METEXO Engineering, France
}

\author{
Laurent SARGER, Professor - Université BORDEAUX 1, France
}

\section{Introduction}

The competitive cluster "Route des Lasers" has been labeled by the French Government in July 2005.

Its main purpose is to become:

- the reference in the development and in the outreach of innovative technologies of optics and lasers (laser systems and applications, metrology, and imaging, innovative physics) in the industrial sectors, as aeronautics, space and embedded systems, health, vision, chemistry, food industry, electronics...

- the center of excellence in research for its specialities: intense lasers, fiber lasers, ultra short lasers, ultrafast optical instrumentation...

- the leader for training on lasers and optics. In this respect, its target is to set-up in Aquitaine another major economic sector, creating jobs and becoming attractive to industrial researchers.

In this context, it has launched in September 2005, in cooperation with Commissariat à l'Energie Atomique (CEA) and Regional Council a project involving scientific exhibitions, called "Terre des Lasers ${ }^{\circledR}$ ", in order to create an exhibition and an area of communication and science discovery or a very large target (public, school, industry) in the fields of optics, lasers, optronics and imaging.

This initiative is part of the strategy of the "Route des Lasers" center which aims to promote technologies developed in the areas of photonics, targeting in particular children and teenagers and their awareness for this particular industrial and scientific topic.

\section{The project}

It consists of three steps.

- The first step is operational and accessible to the public (www.ilp.u-bordeaux1.fr/ILP). Dedicated to high-power lasers, and located in the Plasma \& Laser Institute (close to the CEA center), it consists in:

- a "scale 1" model of a line of MegaJoule Laser (LMJ) and a computer-based representation explaining the operation of a power laser and of fusion;

- operational optical components from older power lasers or LMJ prototypes;

- two rooms for practical and technical trainings, introducing high schools students to physics experimentations required by the Public Education Authority of Bordeaux (Rectorat de l'Académie de Bordeaux).

- a website (in progress).
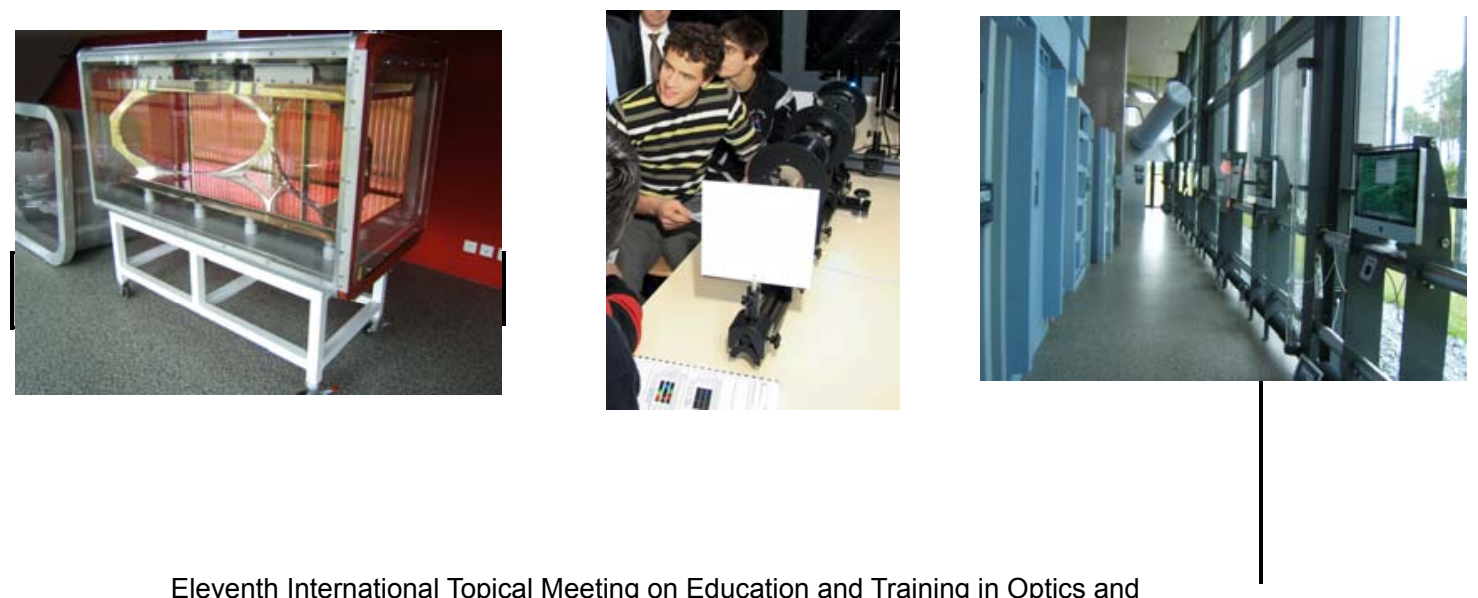

Eleventh International Topical Meeting on Education and Training in Optics and

Photonics, edited by K. Alan Shore, Deb Kane, Proc. of SPIE Vol. 9666, 96660D

(C) 2009 SPIE, OSA, IEEE, ICO · doi: 10.1117/12.2208022 
- The second step is going to start. Based on travelling exhibitions being held by professionals, it has two goals:

- Stimulate and educate:

- stimulate and educate the public to the world of optics and lasers, prioritarizing children and schools, who would be the future actors;

- stimulate scientific and entrepreneurial vocations, facilitate a better communication between researchers and public.

- understanding, by experiments, the physical principles and the scientific and industrial applications in the optics areas, and in particular lasers, to:

- a various public: families, students, scientists, industrialists, journalists,

- a public with very different expectations and scientific knowledge,

- an international public.

- Broadcast information during major events (cultural, economical or social) in Aquitaine, in France and in some European cities, being representative of the "Route des Lasers " project.

- The third step, synchronised with the 2012 opening of LMJ, consists in the completion of the building to receive the exhibitions.

\section{Exhibitions:}

There will be two:

- a main exhibition of approximately $500 \mathrm{~m} 2$, operational in 2011 , which will first be held in prestigious places in France and in Europe (Palais de la Découverte in Paris, Deutsche Museum in Munich, Kutxaespacio de la Ciencia in San Sebastian, Bordeaux ...), before its final integration into its future permanent building. In this respect, the architecture will be chosen to highlight the goals of the center.

- a travelling exhibition of approx. $150 \mathrm{~m} 2$ :

- consisting in part of the previous exhibition, easily transportable;

- autonomous;

- adapted to all kind of premises: professional shows and schools.

- a website setting up and keeping tracks of these exhibitions.

The scientific contents of the exhibitions will be defined and validated by a scientific industrial and educational committee involving French and European representatives (university, research, industry).

Our approach for the transfer of knowledge is multiform and adapted to the audience:

- Free visits or guided tours of the exhibition:

- The chosen design of the scenes will aim to dive and accompany the visitor to the wonderful world of light. Guideline will be the Laser and its applications in low or high energy.

- Will be presented all the thematic in order to understand the functioning (optics, fusion energy, inertial confinement fusion, plasmas) and the resulting applications (medicine, industrial applications, astrophysics, etc).

- The exhibition will include an historical part, a discovery part (free-access manipulations and touch screens to experiment and go beyond the simple observation) and live experiences. 
- The performance of experiments in or near schools, tailored to the educational programs and using kits. These experiments may be performed individually or by scientist.

\section{Present situation}

Several awareness projects have been completed or are being discussed in the scientific community:

- existing projects

- the Network of Excellence NEMO (Network of Excellence on Micro Optics) of the 6th PCRD: creation of an educational kit in the field of micro-optics to educate students, from primary school until the end of the secondary, applications and the role of optics and micro-optics in everyday life or in research,

- the travelling exhibition "Fascination of Light - Light for Schools", supported by the German Ministry of Education and Research (BMBF),

- the "Kid's Science Museum of Photons", with whom we signed a partnership.

- projects being set up:

- "Photonics Explorer", driven by the University of Brussels, with the objective to develop a kit to develop awareness of the photonics low cost for wide broadcast in schools,

- Completion in Barcelona of a museum dedicated to photonics.

\section{Collaborations requests}

We are looking for partnerships to capitalise the work already done and planned (known or unknown) in the area of photonics, targeting in particular schools.

We offer, to those who wish to be involved, to join the Scientific and Educational enlarged Committee, in order to define together the themes and tools that will be developed in the context of our project.

J ean Paul PRULHI ERE email: jean-paul.prulhiere@laposte.net

Laurent SARGER email: laurent.sarger@u-bordeaux1.fr 